\title{
Prevalence of helicobacter pylori infection among children living in a rural setting in Sub-Saharan Africa
}

\author{
Yaw Asante Awuku*, David Larbi Simpong², Ishmael Kunateh Alhassan², Derek Anamaale Tuoyire³,
} Taiba $\mathrm{Afa}^{4}$ and Patrick Adu ${ }^{2}$

\begin{abstract}
Background: Helicobacter pylori infection affects more than half of the world's population. It is generally acquired during childhood with no symptoms but has long- term clinical sequelae. This study estimated the prevalence of $\mathrm{H}$. pylori infection amongst children in a rural environment in Africa.

Methods: We conducted a cross-sectional study over a four (4)-month period within two rural communities. 240 asymptomatic children were tested using lateral flow immunochromatographic assay for the qualitative detection of $\mathrm{H}$. pylori antigen in a fecal specimen. Statistical analysis and processing was done using Stata version 11.

Results: The mean age of the participants was $10.5 \pm 2.7$ years with the predominant age range being $8-10$ years (34.6\%), and a mean household size of $7.1 \pm 1.7$. The study population showed a female preponderance of $57.1 \%$. $88 \%$ of the $\mathrm{H}$. pylori positive children lacked pipe and borehole drinking water. All of the positive $\mathrm{H}$. pylori children practiced open-air defecation. The overall prevalence of $\mathrm{H}$. pylori infection among children in this study was at least $14.2 \%$.

Conclusion: Our study demonstrated a high prevalence of $\mathrm{H}$. pylori infection among children in a rural setting. Educational status of parents did not affect $\mathrm{H}$. pylori prevalence but increasing household numbers, female gender, source of drinking water other than pipe and borehole, open-air defecation and younger age were associated with a higher $\mathrm{H}$. pylori prevalence.
\end{abstract}

Keywords: H.pylori infection, Prevalence, Immune chromatographic assay, Children and Ghana

\section{Background}

Helicobacter pylori (H. pylori) is an important global infection with a worldwide prevalence of about $50 \%[1,2]$. This infection is mostly acquired during childhood through the fecal-oral and oral-oral route [3, 4]. Initial infection with this organism is usually silent but symptoms and pathologic changes occur later in life. The clinical conditions and pathologic changes associated with $H$. pylori infection include gastritis, gastric and duodenal ulcers, gastric cancers, iron deficiency anaemia and idiopathic thrombocytopenic purpura (ITP) [5-8]. H. pylori infection exhibits a varied geographic

\footnotetext{
* Correspondence: ppawuku@gmail.com

'Department of Medicine and Therapeutics, University of Cape Coast, Cape Coast, Ghana

Full list of author information is available at the end of the article
}

distribution on both local and global scales. These variations are mostly socioeconomically driven; factors such as age, gender, genetic predisposition, ethnicity, educational level and sanitation determine the incidence and prevalence of this global infection [9-11].

The diagnosis of $\mathrm{H}$. pylori infection is generally based on methods described as invasive or non-invasive approaches. The invasive methods are based on endoscopy and biopsy using modalities like culture, histology and rapid urease test. Non-invasive diagnostic methods include urea breath test (UBT), fecal antigen testing, serology and more recently polymerase chain reaction testing of feces. The sensitivities of the invasive and non-invasive tests are comparable and relevant in clinical practice [12, 13]. This study used the lateral flow 
monoclonal immune-chromatographic testing (ICT) technique to determine the prevalence of $H$. pylori among children.

The primary objective of this study was to determine the prevalence of $\mathrm{H}$. pylori infection among the pediatric population in a rural West African setting.

Additionally, we evaluated the sociocultural and demographic factors influencing the prevalence of this infection in the communities.

\section{Methods}

\section{Study population and design}

This cross-sectional study was conducted from December 2014 to March 2015 within two rural communities in the Upper West region of Ghana. The Upper West is located at the North western corner of Ghana with latitude $9.8^{\circ}$ $11.0^{\circ}$ north and longitude $1.6^{\circ}-3.0^{\circ}$ west, bounded to Burkina Faso to the north. A total of 240 children ( $\leq 16$ years) were recruited for the study. This was done by assigning the students' numbers 1 and 2 with all those numbered 2 selected for this study. Informed consent was obtained through community leaders, teachers and parents of those who participated in the study.

\section{Demographic details}

The age, gender, type of toilet facility, source of drinking water, number of people in their household, number of siblings, and the educational level of the children as well as their parents were collected from all participants using a structured questionnaire.

\section{Helicobacter pylori testing}

Participants were given clean stool sample containers to provide fresh stool samples within $2 \mathrm{~h}$ in the sterilized containers provided.The children were asked to indicate the time and date of specimen collection. As an exclusion criteria, any specimen that lasted for more than $2 \mathrm{~h}$ before reaching us was discarded. All stool specimen were collected during their morning $(7: 00 \mathrm{am})$ assembly section and transported in a cold $\left(-4{ }^{\circ} \mathrm{C}\right)$ specimen carrier to the laboratory. Specimen that we anticipated will stay more than $2 \mathrm{~h}$ before processing (from time indicated on the container and the time of testing) in the laboratory were refrigerated at $\left(-20{ }^{\circ} \mathrm{C}\right)$. Eight samples in all were discarded with reference to the exclusion criteria defined in sample collection.

A lateral flow immunochromatographic assay for the qualitative detection of Helicobacter pylori antigen in human fecal specimen (OnSite H. pylori Ag Rapid Test, USA) was used.

\section{Statistics}

The data was captured using Microsoft excel, 2007 and exported to STATA version 11.0 for processing and analysis. Univariate and bivariate analysis were used to describe the results in the form of frequency and percentage distributions. Pearson's chi squared and Fisher's exact tests employed to test associations between various background characteristics of participants and the outcome of interest (H. pylori status) at $p<0.05$ significance level.

\section{Results}

\section{Characteristics of study population}

The participant characteristics are as presented in Table 1. The mean age of the participants was $10.5 \pm 2.7$ years. The predominant age range was $8-10$ years constituting $34.6 \%$. However, the age group with the highest incidence of $H$. pylori infection was 5-7 years that had $19.5 \%$ positivity. The age group with the least $H$. pylori infection rate was 14-16 years with prevalence of $11.9 \%$. The study population showed a female: male ratio of 1.3:1, with a higher proportion of females having $H$. pylori infection compared to males [16.8\% (females) vs $10.7 \%$ (males)].

Table 2 stratifies the study participants with regards to $H$. pylori infection and its association with educational level of parents and household size. The educational level of either parent was not significantly associated with $H$. pylori infection rate. The mean household size of the study participants was $7.1 \pm 1.7$. Interestingly, participant household size was significantly associated with the prevalence of $H$. pylori infection $(p=0.000$; Fisher's exact test).

Table 3 stratifies the H. pylori infection status of the participants with regards to number of siblings and lifestyle choices. Overall, $14.2 \%$ of the participants had $H$. pylori infection. About $48.3 \%$ of the participants had no access to pipe/borehole as a source of water. Whereas $25.9 \%$ (116/240) of those having no access to pipe/borehole were $H$. pylori positive, only $3.2 \%$ of those with pipe/borehole were $H$. pylori positive. This difference was statistically significant ( $p=0.000$; Fisher's exact test). Overall, $88 \%$ (30/34) of the $\mathrm{H}$. pylori stool antigen positive participants lacked pipe/borehole drinking water. In addition, $70.4 \%(169 / 240)$ of the participants practiced open air defaecation. Not surprisingly, $20.1 \%$ of those practicing open-air defaecation were $H$ pylori positive, none of the participants using pit/wc was $H$. pylori positive.

\section{Discussion}

H. pylori infection affects more than half of the world's population including children. Because of the fecal-oral mode of transmission it is more prevalent in poor socioeconomic environments. $H$. pylori is described in current medical literature as a group 1 carcinogen but the health implications of infection in children remains uncertain [2]. This may be problematic particularly in 
Table 1 Distribution of sample characteristics

\begin{tabular}{|c|c|c|c|c|}
\hline \multirow[b]{3}{*}{ Characteristic } & \multicolumn{2}{|c|}{ H. Pylori Status } & \multirow[b]{3}{*}{ Total } & \multirow[b]{3}{*}{$95 \% \mathrm{Cl}$} \\
\hline & Negative & Positive & & \\
\hline & N (\%) & N (\%) & & \\
\hline Participants & $206(85.8)$ & $34(14.2)$ & 240 & $0.097,0.186$ \\
\hline \multicolumn{5}{|l|}{ AGE } \\
\hline $5-7$ & $33(80.5)$ & $8(19.5)$ & 41 & $0.068,0.321$ \\
\hline $8-10$ & $73(87.9)$ & $10(12.1)$ & 83 & $0.048,0.191$ \\
\hline $11-13$ & $63(85.1)$ & $11(14.9)$ & 74 & $0.656,0.231$ \\
\hline $14-16$ & $37(88.1)$ & $5(11.9)$ & 42 & $0.016,0.221$ \\
\hline \multicolumn{5}{|l|}{ Pearson chi2 $(1)=1.4762 \operatorname{Pr}=0.688$} \\
\hline \multicolumn{5}{|l|}{ SEX } \\
\hline Female & $114(83.2)$ & $23(16.8)$ & 137 & $0.104,0.231$ \\
\hline Male & $92(89.3)$ & $11(10.7)$ & 103 & $0.461,0167$ \\
\hline Pearson $\operatorname{chi} 2(1)=1.8044 \mathrm{Pr}=0.179$ & & & & \\
\hline
\end{tabular}

African children who may harbor more virulent strains. The long term sequelae of $\mathrm{H}$. pylori infection was ignored because of what has been described as "African enigma" [6]. It has however been shown that all complications including carcinoma do occur in the African population $[6,14]$. Our study used a noninvasive method to qualitatively detect $H$. pylori antigen in human fecal specimen. We acknowledge the limitation in testing as the $H$. pylori stool antigen testing was not compared with any gold standard diagnostic method. However, the ethical and feasibility challenges of upper gastrointestinal endoscopy as a screening tool in an asymptomatic pediatric population was strongly considered [15].

The global prevalence of $\mathrm{H}$. pylori infection is generally higher in developing countries than the developed world $[16,17]$. Transmission of $H$. pylori infection is rapidly decreasing in the developed countries predictably because of improvement in the sanitation $[18,19]$. There

Table 2 Association of $\mathrm{H}$. pylori infection with parent education and household size

\begin{tabular}{|c|c|c|c|c|}
\hline \multirow[b]{3}{*}{ Characteristic } & \multicolumn{2}{|c|}{ H. Pylori Status } & \multirow[b]{3}{*}{ Total } & \multirow[b]{3}{*}{$95 \% \mathrm{Cl}$} \\
\hline & Negative & $\overline{\text { Positive }}$ & & \\
\hline & N (\%) & N (\%) & & \\
\hline \multicolumn{5}{|c|}{ Mother's Edu. Status } \\
\hline No & $170(85.9)$ & $28(14.1)$ & 198 & $0.092,0.190$ \\
\hline Yes & $36(85.7)$ & $6(14.3)$ & 42 & $0.032,0.253$ \\
\hline \multicolumn{5}{|c|}{ Pearson chi2(1) $=0.0006 \operatorname{Pr}=0.981$} \\
\hline \multicolumn{5}{|c|}{ Father's Edu. Status } \\
\hline No & $140(86.4)$ & $22(13.6)$ & 162 & $0.824,0.189$ \\
\hline Yes & $66(84.6)$ & $12(15.4)$ & 78 & $0.071,0.235$ \\
\hline \multicolumn{5}{|c|}{ Pearson chi2 $(1)=0.1410 \operatorname{Pr}=0.707$} \\
\hline \multicolumn{5}{|c|}{ No. of People in a Household } \\
\hline 4 & $11(84.6)$ & $2(15.4)$ & 13 & $0.073,0.380$ \\
\hline 5 & $20(60.6)$ & $13(39.4)$ & 33 & $0.217,0.569$ \\
\hline 6 & $22(56.4)$ & $17(43.6)$ & 39 & $0.273,0.598$ \\
\hline 7 & $51(96.2)$ & $2(3.8)$ & 53 & $0.015,0.090$ \\
\hline 8 & $43(100)$ & 0 & 43 & - \\
\hline 9 & $41(100)$ & 0 & 41 & - \\
\hline 10 & $18(100)$ & 0 & 18 & - \\
\hline Fisher's exa & & & & \\
\hline
\end{tabular}


Table 3 Association of H. pylori infection with lifestyle choices

\begin{tabular}{|c|c|c|c|c|}
\hline \multirow[b]{3}{*}{ Characteristic } & \multicolumn{2}{|c|}{ H. Pylori Status } & \multirow[b]{3}{*}{ Total } & \multirow[b]{3}{*}{$95 \%$ Cl } \\
\hline & Negative & Positive & & \\
\hline & N (\%) & N (\%) & & \\
\hline \multicolumn{5}{|l|}{ Number of siblings } \\
\hline $1-3$ & $103(75.2)$ & $34(24.8)$ & 137 & $0.174,0.321$ \\
\hline $4+$ & $103(100 \%)$ & 0 & 103 & - \\
\hline \multicolumn{5}{|l|}{ Fischer's exact test: $p=0.000$} \\
\hline \multicolumn{5}{|l|}{ Pets/Livestock } \\
\hline None & $62(64.6)$ & $34(35.4)$ & 96 & $0.256,0.451$ \\
\hline Pet & $49(100)$ & 0 & 49 & - \\
\hline 2 livestock & $95(100)$ & 0 & 95 & - \\
\hline \multicolumn{5}{|l|}{ Fischer's exact test: $p=0.000$} \\
\hline \multicolumn{5}{|l|}{ Source of drinking water } \\
\hline Pipe/borehole & $120(96.8)$ & $4(3.2)$ & 124 & $0.001,0.063$ \\
\hline Other than pipe/borehole & $86(74.1)$ & $30(25.9)$ & 116 & $0.177,0.339$ \\
\hline \multicolumn{5}{|l|}{ Fisher's exact test: $\operatorname{Pr}=0.000$} \\
\hline \multicolumn{5}{|l|}{ Type of laterine facility } \\
\hline Open air & $135(79.9)$ & $34(20.1)$ & 169 & $0.140,2.262$ \\
\hline Pit/WC & 71 (100) & 0 & 71 & - \\
\hline
\end{tabular}

is infrequent $H$. pylori infection during childhood in the developed countries with the United States reporting less than $5 \%$ in under five years and up to $10 \%$ by adolescent age. However in developing countries the story is different with about $50 \%$ of children under five infected and as high as $90 \%$ in some adult populations [20,21]. We demonstrated a prevalence of at least $14.2 \%$ among asymptomatic children between the ages of 5-16 years living in a rural setting in sub-Saharan Africa (SSA). Our finding in terms of prevalence of $\mathrm{H}$. pylori infection among children was not consistent with the developing countries data [22-24]. This could be attributed to the differences in the study design, population dynamics, as well as the specificities of techniques employed in the studies. Antibody testing procedures for $\mathrm{H}$. pylori detection are used in some studies but is unable to differentiate active infection from a previous in the early weeks of follow up after eradication therapy. Our study employed H. pylori stool antigen testing methods because of its non-invasive nature especially in a children population.

Our study had a female preponderance of $57.1 \%$ with higher $\mathrm{H}$. pylori prevalence among females $(16.8 \%)$ than males (10.7\%). The gender effect on prevalence of $H$. pylori infection in many populations is varied. Woodward and colleagues reported a higher prevalence in men than women $[20,23]$ whiles others reported no difference. A meta-analysis reported a male predominance in adults but not in children $[19,25,26]$. Our study in children demonstrated a higher prevalence in females with no plausible explanation.
The age effect on prevalence is well documented in $\mathrm{H}$. pylori epidemiology with a positive correlation between age and prevalence [27, 28]. Our study showed higher prevalence in the younger age group and decreasing prevalence with advancing age. This is a reverse of the pattern in most population studies. Educational status has been used as a proxy marker of socioeconomic status and an important determinant of $H$. pylori prevalence in developed and resource limited settings [29-31]. The educational status of parents in our study did not affect the prevalence significantly. Crowding in households and increasing household contact have been linked as risk factors of $H$. pylori infection [32, 33]. As the number of people in a household increased the prevalence of $H$. pylori also increased [34]. Source of drinking water other than pipe and borehole increased the prevalence of $\mathrm{H}$. pylori infection as well as open-air defecation. Water is an important source of $\mathrm{H}$. pylori spread and many studies have actually confirmed it. Therefore, handling of water and poor sanitation will be a good milieu for the spread of this infection. Our study support this assertion as we also realized that source of water other than pipe and borehole and open air defecation were associated with higher prevalence of $\mathrm{H}$. pylori infection $[35,36]$.

In our environment, poverty and poor socioeconomic status are associated with higher household numbers. It is therefore not surprising giving the mode of transmission that prevalence in our study increased with increasing household numbers. Proper hand washing and waste disposing systems will help 
control infection in households especially in crowded places.

\section{Conclusion}

Our study demonstrated a high prevalence of $\mathrm{H}$. pylori infection among children in a rural setting. Educational status of parents did not affect $\mathrm{H}$. pylori prevalence but increasing household numbers, female gender, younger age, open-air defecation and source of drinking water other than pipe and borehole were associated with a higher prevalence.

\section{Abbreviations}

ICT: Immune chromatographic testing; ITP: Idiopathic thrombocytopenic purpura; UBT: Urease Breath Test

\section{Acknowledgements}

We acknowledge the parents,teachers and elders of the communities for their support during the data collection.

\section{Funding}

Self funded by authors.

\section{Availability of data and materials}

The datasets during and/or analysed during the current study is available from the corresponding author on reasonable request.

\section{Authors' contributions}

YAA concept, wrote and reviewed manuscript, DLS concept, data collection and reviewed manuscript, IKA data collection, DAT statistical analysis, TA reviewed manuscript, PA statistical display of results and reviewed manuscript. All authors read and approved the final manuscript.

\section{Competing interests}

The authors declare that they have no competing interests.

\section{Consent for publication}

Not applicable.

\section{Ethics approval and consent to participate}

Approval was obtained from the University of Cape Coast, Institutional Review Board for the conduct of this research work and publication. Informed consent was obtained from the parents and guardians of the study participants.

\section{Publisher's Note}

Springer Nature remains neutral with regard to jurisdictional claims in published maps and institutional affiliations.

\section{Author details}

'Department of Medicine and Therapeutics, University of Cape Coast, Cape Coast, Ghana. ${ }^{2}$ Department of Medical Laboratory Technology, University of Cape Coast, Cape Coast, Ghana. ${ }^{3}$ Department of Community Medicine, Universty of Cape Coast, Cape Coast, Ghana. ${ }^{4}$ Department of Child Health, University of Ghana, Accra, Ghana.

Received: 12 July 2016 Accepted: 20 April 2017

Published online: 24 April 2017

\section{References}

1. Go MF. Review article: natural history and epidemiology of Helicobacter pylori infection. Aliment Pharmacol Ther. 2002;16(Suppl 1):3-15.

2. Cancer, I.A.f.R.o, International Agency for Research on Cancer Working Group on the Evaluation of Carcinogenic Risks to Humans., in Helicobacter pylori. Schistosomes, Liver Flukes and Helicobacter pylori. Lyon, France: International Agency for Research; 1994. p. 177-240.

3. Malaty HM, et al. Age at acquisition of Helicobacter pylori infection: a follow-up study from infancy to adulthood. Lancet. 2002;359(9310):931-5.
4. Parsonnet J, Shmuely H, Haggerty T. Fecal and oral shedding of Helicobacter pylori from healthy infected adults. JAMA. 1999;282(23):2240-5.

5. Bittencourt PF, et al. Gastroduodenal peptic ulcer and Helicobacter pylori infection in children and adolescents. J Pediatr. 2006;82(5):325-34.

6. Agha A, Graham DY. Evidence-based examination of the African enigma in relation to Helicobacter pylori infection. Scand J Gastroenterol. 2005:40(5):523-9.

7. Gasbarrini A, et al. Regression of autoimmune thrombocytopenia after eradication of Helicobacter pylori. Lancet. 1998;352(9131):878.

8. Franchini $\mathrm{M}$, et al. Effect of Helicobacter pylori eradication on platelet count in idiopathic thrombocytopenic purpura: a systematic review and metaanalysis. J Antimicrob Chemother. 2007;60(2):237-46.

9. Malaty HM, et al. Natural history of Helicobacter pylori infection in childhood: 12-year follow-up cohort study in a biracial community. Clin Infect Dis. 1999;28(2):279-82.

10. Pounder RE, Ng D. The prevalence of Helicobacter pylori infection in different countries. Aliment Pharmacol Ther. 1995;9(Suppl 2):33-9.

11. Archampong TN, Asmah RH, Wiredu E, Gyasi RK, Nkrumah KN, Rajakumar K. Epidemiology of Helicobacter pylori infection in dyspeptic Ghanaian patients. Pan Afr Med J. 2015;20:178.

12. Megraud F, European Paediatric Task Force on Helicobacter pylori. Comparison of non-invasive tests to detect Helicobacter pylori infection in children and adolescents: results of a multicenter European study. J Pediatr. 2005;146(2):198-203.

13. Gisbert JP, Pajares JM. Stool antigen test for the diagnosis of Helicobacter pylori infection: a systematic review. Helicobacter. 2004;9(4):347-68.

14. Segal I, Ally R, Mitchell H. Helicobacter pylori-an African perspective. QJM. 2001;94(10):561-5.

15. Bourke B, et al. Canadian Helicobacter Study Group Consensus Conference: Update on the approach to Helicobacter pylori infection in children and adolescents-an evidence-based evaluation. Can J Gastroenterol. 2005;19(7):399-408.

16. Perez-Perez Gl, Rothenbacher D, Brenner H. Epidemiology of Helicobacter pylori infection. Helicobacter. 2004;9(Suppl 1):1-6.

17. Salih BA. Helicobacter pylori infection in developing countries: the burden for how long? Saudi J Gastroenterol. 2009;15(3):201-7.

18. Brown LM. Helicobacter pylori: epidemiology and routes of transmission. Epidemiol Rev. 2000;22(2):283-97.

19. Khalifa MM, Sharaf RR, Aziz RK. Helicobacter pylori: a poor man's gut pathogen? Gut Pathog. 2010;2(1):2.

20. Weaver LT. Royal Society of Tropical Medicine and Hygiene Meeting at Manson House, London, 16 February 1995. Aspects of Helicobacter pylori infection in the developing and developed world. Helicobacter pylori infection, nutrition and growth of West African infants. Trans R Soc Trop Med Hyg. 1995;89(4):347-50.

21. Rothenbacher D, Brenner H. Burden of Helicobacter pylori and H. pylorirelated diseases in developed countries: recent developments and future implications. Microbes Infect. 2003:5(8):693-703.

22. Bassily $\mathrm{S}$, et al. Seroprevalence of Helicobacter pylori among Egyptian newborns and their mothers: a preliminary report. AmJTrop Med Hyg. 1999;61(1):37-40.

23. Frenck RW Jr, et al. Sensitivity and specificity of various tests for the diagnosis of Helicobacter pylori in Egyptian children. Pediatrics. 2006;118(4):e1195-202.

24. Abd El-Latif AM, Ali ASA, Abdel-Hady M, Borai MBM. Seroprevalence of Helicobacter Pylori in Secondary Immunocompromised Children. J Am Sci. 2011;7(9):592-5.

25. de Martel C, Parsonnet J. Helicobacter pylori infection and gender: a meta-analysis of population-based prevalence surveys. Dig Dis Sci. 2006;51(12):2292-301.

26. Woodward M, Morrison C, McColl K. An investigation into factors associated with Helicobacter pylori infection. J Clin Epidemiol. 2000;53(2):175-81.

27. Breuer $T$, et al. Prevalence of and risk factors for Helicobacter pylori infection in the western part of Germany. Eur J Gastroenterol Hepatol. 1996;8(1):47-52.

28. Cherian S, et al. The epidemiology of Helicobacter pylori infection in African refugee children resettled in Australia. Med J Aust. 2008;189(8):438-41.

29. Lopes Al, Vale FF, Oleastro M. Helicobacter pylori infection - recent developments in diagnosis. World J Gastroenterol. 2014;20(28):9299-313.

30. Darko R, et al. Changing Patterns of the Prevalence of Helicobacter Pylori Among Patients at a Corporate Hospital in Ghana. Ghana Med J. 2015;49(3):147-53.

31. Campuzano-Maya G. Hematologic manifestations of Helicobacter pylori infection. World J Gastroenterol. 2014;20(36):12818-38. 
32. Rosenstock SJ, et al. Socioeconomic factors in Helicobacter pylori infection among Danish adults. Am J Public Health. 1996;86(11):1539-44.

33. Mendall MA, et al. Childhood living conditions and Helicobacter pylori seropositivity in adult life. Lancet. 1992;339(8798):896-7.

34. McCallion WA, et al. Helicobacter pylori infection in children: relation with current household living conditions. Gut. 1996;39(1):18-21.

35. Banda $\mathrm{K}$, et al. Water handling, sanitation and defecation practices in rural southern India: a knowledge, attitudes and practices study. Trans R Soc Trop Med Hyg. 2007;101(11):1124-30.

36. Aziz RK, Khalifa MM, Sharaf RR. Contaminated water as a source of Helicobacter pylori infection: A review. J Adv Res. 2015;6(4):539-47.

Submit your next manuscript to BioMed Central and we will help you at every step:

- We accept pre-submission inquiries

- Our selector tool helps you to find the most relevant journal

- We provide round the clock customer support

- Convenient online submission

- Thorough peer review

- Inclusion in PubMed and all major indexing services

- Maximum visibility for your research

Submit your manuscript at www.biomedcentral.com/submit
(O) BioMed Central 